\title{
Colon Inflammatory Polyp
}

National Cancer Institute

\section{Source}

National Cancer Institute. Colon Inflammatory Polyp. NCI Thesaurus. Code C5517.

A non-neoplastic polypoid lesion in the colon. It may arise in a background of

inflammatory bowel disease or colitis. It is characterized by the presence of a distorted epithelium, inflammation, and fibrosis. 